\title{
Abatement of epileptic spike-wave discharges through single pulse stimulation
}

\author{
Peter N Taylor ${ }^{{ }^{*} \dagger}$, Yujiang Wang ${ }^{2+}$, Justin Dauwels ${ }^{1}$, Gerold Baier $^{3}$ \\ From Twenty Second Annual Computational Neuroscience Meeting: CNS*2013 \\ Paris, France. 13-18 July 2013
}

Spike-wave discharges (SWD) are a striking phenomena detectable on the electroencephalogram (EEG) of all patients during absence seizures. There is experimental and clinical evidence to suggest that seizures can be terminated early through the use of short auditory stimulation [1], however, stimulation protocols for seizure abatement are underdeveloped and their varied success is poorly understood.

In this work we extend the model of [2] to account for known thalamocortical connectivity which has previously been implicated in SWD [3]. This model is capable of producing transient spike-wave trains upon perturbation, for example, through the inclusion of noise. We show that a single pulse perturbation during a simulated seizure can, if applied with the correct timing and amplitude, successfully terminate the seizure early (Figure. 1a). Furthermore, if the same stimulus is applied incorrectly (e.g. at a different time) the seizure could be prolonged (Figure. 1b). The complex phase and amplitude dependency of successful stimulation can be explained in the model with its nontrivial phase space configuration. The complex and sensitive dependency could account for the variations in success of different clinical and experimental stimulation studies. Our modeling approach makes the prediction that these optimal stimuli can be predicted through the use of a learning algorithm included in a closed-loop stimulation device as suggested by [1]. Successful clinical implementation and application of such a learning algorithm could have dramatic impact on epileptic patients and

(A)

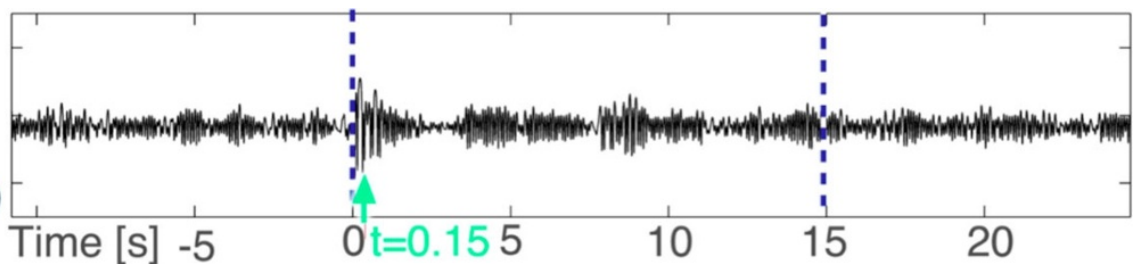

(B)

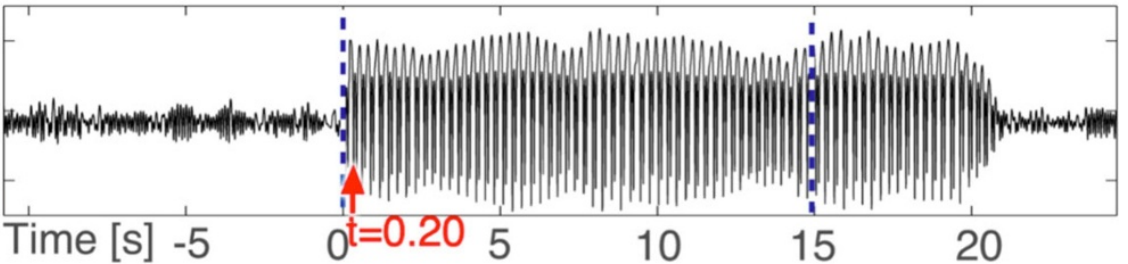

Figure 1 (A) Successful single pulse stimulation applied at $\mathbf{0 . 1 5}$ seconds after seizure onset. Blue dashed line indicates the SWD duration without a stimulus. (B) Unsuccessful single pulsestimulation applied 0.2 seconds after seizure onset.

† Contributed equally

${ }^{1}$ School of Electrical \& Electronic Engineering, Nanyang Technological

University. Singapore

Full list of author information is available at the end of the article

(c) 2013 Taylor et al; licensee BioMed Central Ltd. This is an Open Access article distributed under the terms of the Creative Commons 
offer a potential alternative to anti-epileptic drug based therapy. The combination of animal experiments on seizure control of SWD $[4,5]$ and the current model predictions regarding strength and timing could lead to improved translation into the clinical setting.

\section{Author details}

${ }^{1}$ School of Electrical \& Electronic Engineering, Nanyang Technological University. Singapore. ${ }^{2}$ Manchester Interdisciplinary Biocentre, University of Manchester, UK. ${ }^{3}$ Centre for Organismal Studies, University of Heidelberg, Germany.

Published: 8 July 2013

\section{References}

1. Rajna P, Lona C: Sensory stimulation for inhibition of epileptic seizures. Epilepsia 1989, 30(2):168-174.

2. Taylor PN, Baier G: A spatially extended model for macroscopic spikewave discharges. J Comput. Neurosci 2011, 31(3):679-684.

3. Pinault $D, O^{\prime} B r i e n$ T: Cellular and network mechanisms of geneticallydetermined absence seizures. Thalamus Relat Syst 2005, 3(3):181.

4. Saillet S, Gharbi S, Charvet G, Deransart C, Guillemaud R, Depaulis A, David O: Neural adaptation to responsive stimulation: A comparison of auditory and deep brain stimulation in a rat model of absence epilepsy. Brain Stimul 2012.

5. Berényi A, Belluscio M, Mao D, Buzsáki G: Closed-loop control of epilepsy by transcranial electrical stimulation. Science 2012, 337(6095):735-737.

doi:10.1186/1471-2202-14-S1-P13

Cite this article as: Taylor et al:: Abatement of epileptic spike-wave discharges through single pulse stimulation. BMC Neuroscience 201314 (Suppl 1):P13.

\section{Submit your next manuscript to BioMed Central} and take full advantage of:

- Convenient online submission

- Thorough peer review

- No space constraints or color figure charges

- Immediate publication on acceptance

- Inclusion in PubMed, CAS, Scopus and Google Scholar

- Research which is freely available for redistribution

Submit your manuscript at www.biomedcentral.com/submit 